\title{
Market reaction to the announcement of online sales channel investment in enterprises: Evidence from a relatively stable market environment
}

\author{
Yang Lei ${ }^{1} \cdot$ Qiang Zhou ${ }^{2} \cdot$ Waiman Cheung $^{3} \cdot$ Xiling Cui $^{4}\left(\mathbb{D} \cdot\right.$ Ling Peng $^{5}$
}

Accepted: 6 July 2021

(C) The Author(s), under exclusive licence to Springer Science+Business Media, LLC, part of Springer Nature 2021

\begin{abstract}
Although relevant literature investigates the economic value of online sales channel (OSC) from the perspective of the stock market, knowledge on this topic remains insufficient or unclear because existing studies are conducted under an extremely turbulent market environment and have not considered different aspects. This study aims to examine the topic by focusing on the market reactions to OSC investment from three aspects (namely, the innovativeness, business model and goods types) in a relatively stable market environment to fill in the research gap. Empirical results, obtained using 69 firm-level OSC announcements from October 2002 to September 2007, show that the stock market reacts positively to OSC investment by firms. Additionally, the stock market reactions to OSC investment mainly depend on two key characteristics, namely investment innovativeness and business model applied.
\end{abstract}

Keywords Online sales channel $\cdot$ Event study $\cdot$ Investment innovativeness $\cdot$ Business model · Goods type

\section{Introduction}

After the burst of the Internet bubble in 2000 and the ensuing cool-down period, e-commerce has experienced smooth development. E-commerce began to prosper and reach unprecedented levels of advancement in recent years with new technological innovations such as social media [1, 2] and artificial intelligence [3]. In 2019, global e-commerce sales reached $\$ 3.535$ trillion-nearly $16 \%$ of the total global retail sales - compared with $\$ 2.304$ trillion in 2017, which represented about $10 \%$ of the total retail sales [4]. E-commerce has been classified into three channels based on its different functions: online advertising channel to advertise brands and

Xiling Cui

cuixiling@gmail.com

Extended author information available on the last page of the article 
products, online customer support channel to provide before- and after-sales service, and online sales channel (OSC) to enable customer shopping online [5]. The scope and depth of e-commerce strategy, i.e., the distinct adoption of the above three channels, may result in different consequences [6]. For example, investment in online advertising channel may only increase the number of clicks or page views but do not help to improve firm performance [7]. OSC is believed to be the most direct channel towards firm performance [6]. Surprisingly, most e-commerce firms only publish their brief introduction, contact information, or enquiry forms on their websites $[8,9]$ without providing OSC to facilitate the entire online transaction process. In August 2018, the authors conducted an online study of Fortune 500 companies, and we found that only $60 \%$ of them (297 out of 500 firms) were using OSC while the others only provide some general information on their websites. As previous studies have documented that the e-commerce without OSCs may not lead to significant performance improvement [6], the potential of OSC needs to be further unleashed.

However, the existing literature has some research gaps on the relationship between OSC and firm performance, which may hinder the application of OSC in online business. First, the investigations on the benefits of OSC are still quite rare. Most previous studies investigate e-commerce investment without differentiating between e-commerce channels. However, they could not reach a consensus on the relationship between e-commerce investment and firm performance [e.g. 10, 11-14]. The mixed research findings may keep firm managers from formulating the best e-commerce strategies. Therefore, it is necessary to differentiate OSC from the simple online advertising mode of e-commerce and specifically investigate the investment of e-commerce with OSC and its effect on firm performance.

Second, as a new branch of studies on OSC has emerged in recent years $[15,16]$, the limited existing OSC studies were mostly conducted during an unstable period, which may contaminate the research results. Researchers examine the returns to shareholders from investing in information technology (IT), such as the stock price changes in response to the announcement of IT investment [17-19], as one important indicator of the firm performance. Although the positive returns to shareholders provide the evidence of the future benefits from the planned activities and associated IT investments [10], they are hugely affected by the stability of the stock market. Yet, regarding OSC, most of the existing studies on its market reaction [15, 16, 20] were conducted using data from around the Internet bubble period, during which the stock prices of Internet companies first surged and then plummeted, ${ }^{1}$ as indicated in Fig. 1. These studies provide insights into the market value of OSC, while the results should be cautiously interpreted. Specifically, the true value of OSC may not be accurately examined during such an unstable market condition in which overall market health was affected [12] and investors might have exhibited irrational herding behavior. Therefore, it is necessary to further examine stock market reactions

\footnotetext{
1 From the last half of the 1990s onward, the Internet boom pushed stock indices to record high levels. The Internet bubble burst in March 2000; this low lasted to September 2002, and there was excessive speculation in dot-com companies [21] C. Wollscheid, Rise and Bust of Dot.com Bubble, in: Causes, Characteristics, Examples, GRIN Verlag, Munich, 2012, pp. 27.
} 


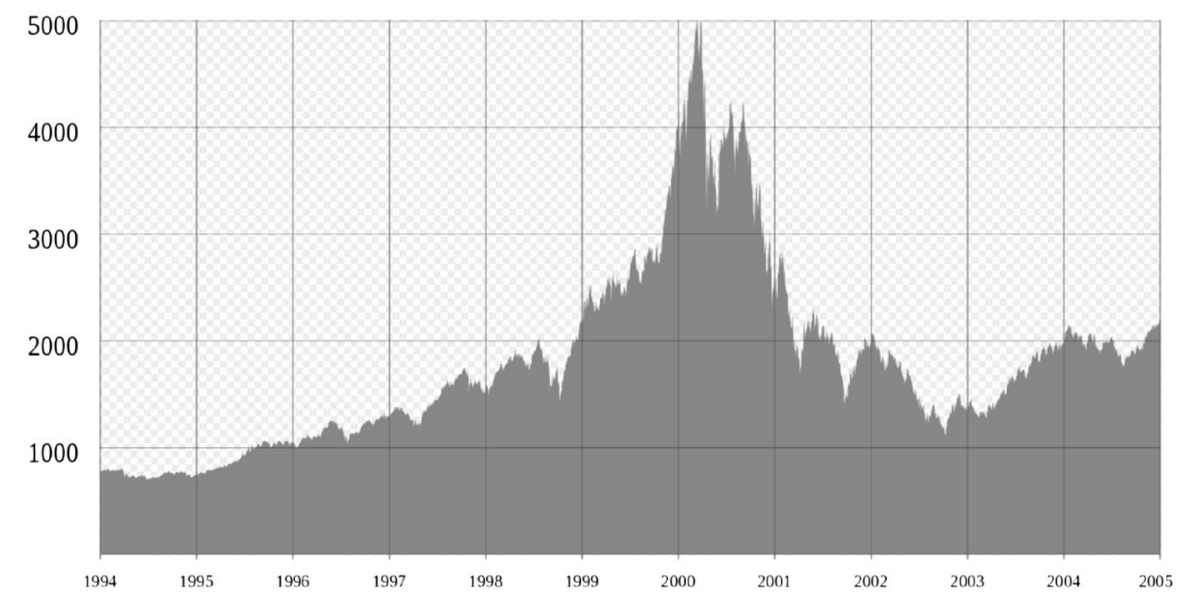

Fig. 1 NASDAQ composite index

to the announcements of OSC investment in a relatively stable market, e.g., after October 2002 [11].

In addition, even for firms that have adopted OSCs, they use different adoption plans and investment strategies. Therefore, it is important to further explore whether these different types of OSC investment are distinct. First, knowledge on the market reaction to the investment innovativeness of an OSC investment, i.e. whether the OSC investment is radical or incremental, is limited [22]. A radical IT investment refers to the first-time of a firm's investment into a specific IT and an incremental one refers to an IT investment to maintain an existing application. Prior studies have found that investors may respond differently to these different types of IT investment [19]. Whether this finding still holds for OSC investments has not been addressed in literature and the moderating effect of investment innovativeness needs to be examined. This study aims to address all the above-mentioned research gaps by investigating the market reaction to OSC investment in a stable market with the consideration of investment innovativeness.

Moreover, this study considers the moderating effects of business model and goods type. The most common business model includes business-to-consumer (B2C) that firms sell products or provide service directly to end consumers and business-to-business (B2B) that firms conduct transactions or business one another, such as a wholesaler and retailer [10]. In addition, the types of goods (tangible or intangible) have been considered as an important contingent factor. Prior studies have confirmed that both business models (B2B or B2C) and goods type of an e-commerce investment announcement affect the generation of a firm's market value [e.g. $10,11]$. Therefore, the moderating effects of these two contextual factors on market reactions to announcements of OSC investment are also examined in this study.

We conduct an event study to further examine the stock price change (outcome) corresponding to OSC investment announcements (events) by considering different situations over a given period of relatively stable market conditions (October 2002 to 
September 2007), in the U.S. market. Using 69 public OSC announcements, we find that the market values firms' OSC announcements positively. Regarding the investment innovativeness, investors value more for firms' first-time OSC investment than subsequent investment, and more for B2B OSC applications than B2C ones. However, we do not observe a significant difference between investors' reactions towards OSC announcements involving different types of goods. In addition, we analyzed the market reactions to those OSC announcements released during the period that the Internet bubble burst (from April 2000 to October 2002) to compare with the main study. The results show that the market reacts negatively to such investment announcements (consistent with some prior studies [12]), which may be contaminated by the market instability. The negative results under such unstable market environment do not truly reflect the value of OSC, further indicating the necessity of the current study and future ones to take the market stability into consideration.

\section{Literature review}

\subsection{Market reaction to the announcement of OSC investment}

The economic value of information technology is one of the most important topics in the IS discipline. A stream of literature on this topic adopts event study from the perspective of stock market evaluation $[17,23]$ to examine the change in a firm's market value when a specific business-related announcement (e.g. IT investment announcement) is released. Such a method has been extensively applied in almost all other business and economic research, such as in marketing [24] and operations and supply chain management [25], as well as in e-commerce literature.

For example, Subramani and Walden [10] examine 251 firms that made e-commerce announcements during the fourth quarter of 1998 and find that they produced a $16.7 \%$ abnormal returns. Extending their work, Dehning et al. [11] use the marketadjusted model and confirm a similar positive abnormal returns for the fourth quarter of 1998, but a nonsignificant result for the fourth quarter of 2000. Later, Dardan et al. [12] examine 349 e-commerce announcements from January 1999 to December 2000 and find that the market reacts positively before March 24, 2000, but negatively to those after that date. Conversely, Ferguson et al. [26] show the market values e-commerce announcements made after March 2000 higher than those made before.

In the e-commerce literature, only a relatively small number of studies have investigated the market value of the specific type of e-commerce, the OSC. Geyskens et al. [20] study the market value of the OSC investment announcements of 93 European newspaper firms and find a positive and significant abnormal returns of $0.71 \%$. Cheng et al. [16] show the positive market reaction to Taiwan banks' OSC announcements. Similarly, Tu [15], by focusing on Taiwan's financial service sector, demonstrates that OSC can positively influence the market value of firms.

Although previous studies provide useful insights into the market value of OSC, most of them were conducted using market data from 1998 to 2001 (or the majority of their samples is within this period), around the Internet bubble, during which the 
stock market fluctuated dramatically, as indicated in the third column of Table 1. Because the stock market perspective is based on the analysis of stock market data, an unstable and unhealthy market environment may not be appropriate and reliable for evaluating the true value of OSC [12]. Most investors may rely on the observation of other investors' actions rather than analyzing the OSC investment of the focal enterprise objectively [11]. Therefore, caution must be exercised when interpreting results derived around the Internet bubble period, and it is imperative to further examine this topic in a relatively stable market environment to provide concrete knowledge for both academia and practice.

\subsection{Contextual factors in prior e-commerce studies}

Besides the direct relationship between information technology investment and the market reaction, investors may react to the same information technology investment differently under different conditions (contextual factors), as indicated in studies on general information technology investment [19], cloud computing initiatives [18], e-commerce outsourcing [27], and websites impairment [28]. By studying the market reaction to e-commerce investment, Subramani and Walden [10] and Dehning et al. [11] investigate firm type (conventional firms and net firms), business model (B2B and B2C), and goods type (tangible goods and intangible goods). The former finds that all three contextual factors matter, while the latter finds that only goods type is a crucial determinant. Ferguson et al. [26] investigates whether the market reacts differently to innovative and non-innovative e-commerce investments, and, surprisingly, find that non-innovative e-commerce investments lead to higher positive reactions than innovative ones. This result contrasts with the findings of prior IT innovative studies that innovative investment leads to more positive market reactions [29]. Researchers believed that when an IT is employed for the first time in a firm, it will enhance intra-firm efficiency and effectiveness, thereby affecting the firm's market value [30]. This counter-intuitive finding deserves further investigation. In addition, although the general e-commerce literature has investigated how the contextual factors, i.e. innovativeness, business model, and goods type, influence the market perceptions to e-commerce investment $[10,11,26]$, the OSC literature lacks investigation of these factors, as indicated in the sixth column of Table 1;

We summarized the e-commerce and OSC event studies in Table 1, in which the publication year, topic, data period, number of samples, country, industry, estimation model, contextual factors, and findings of each study were listed. In addition to the data period and the contextual factors we have discussed above, we also found that the previous OSC event studies mainly focus on some specific industry (although e-commerce event studies may be across different industries), which may hinder readers' comprehensive understanding. Therefore, this study further expands our knowledge about the market value of OSC investment using a relatively stable market data, with more contextual factors and a broader industry scope. 


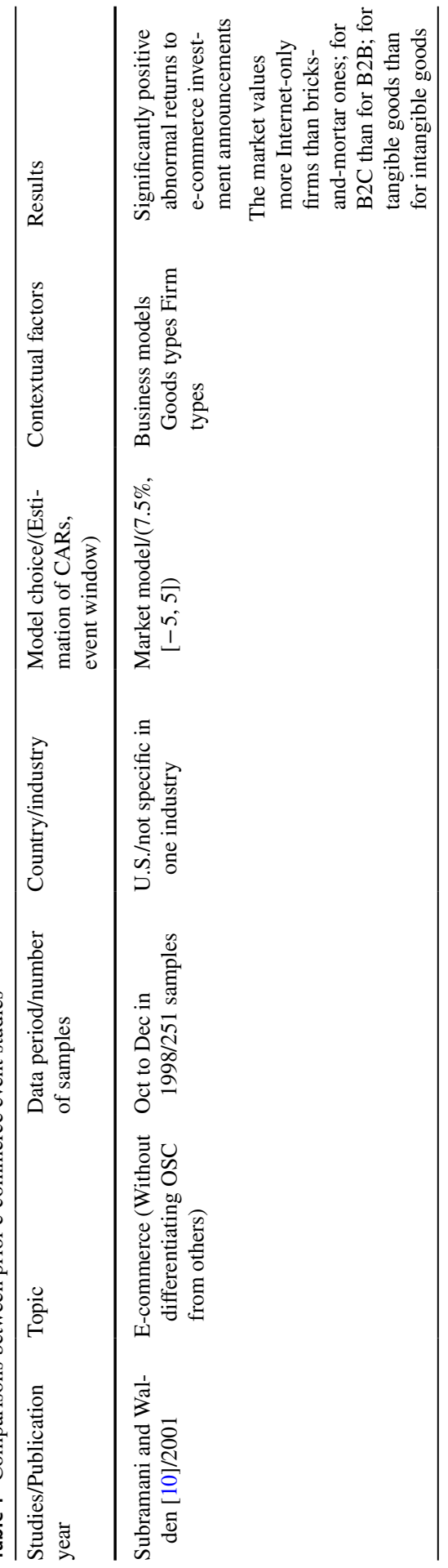

글 Springer 


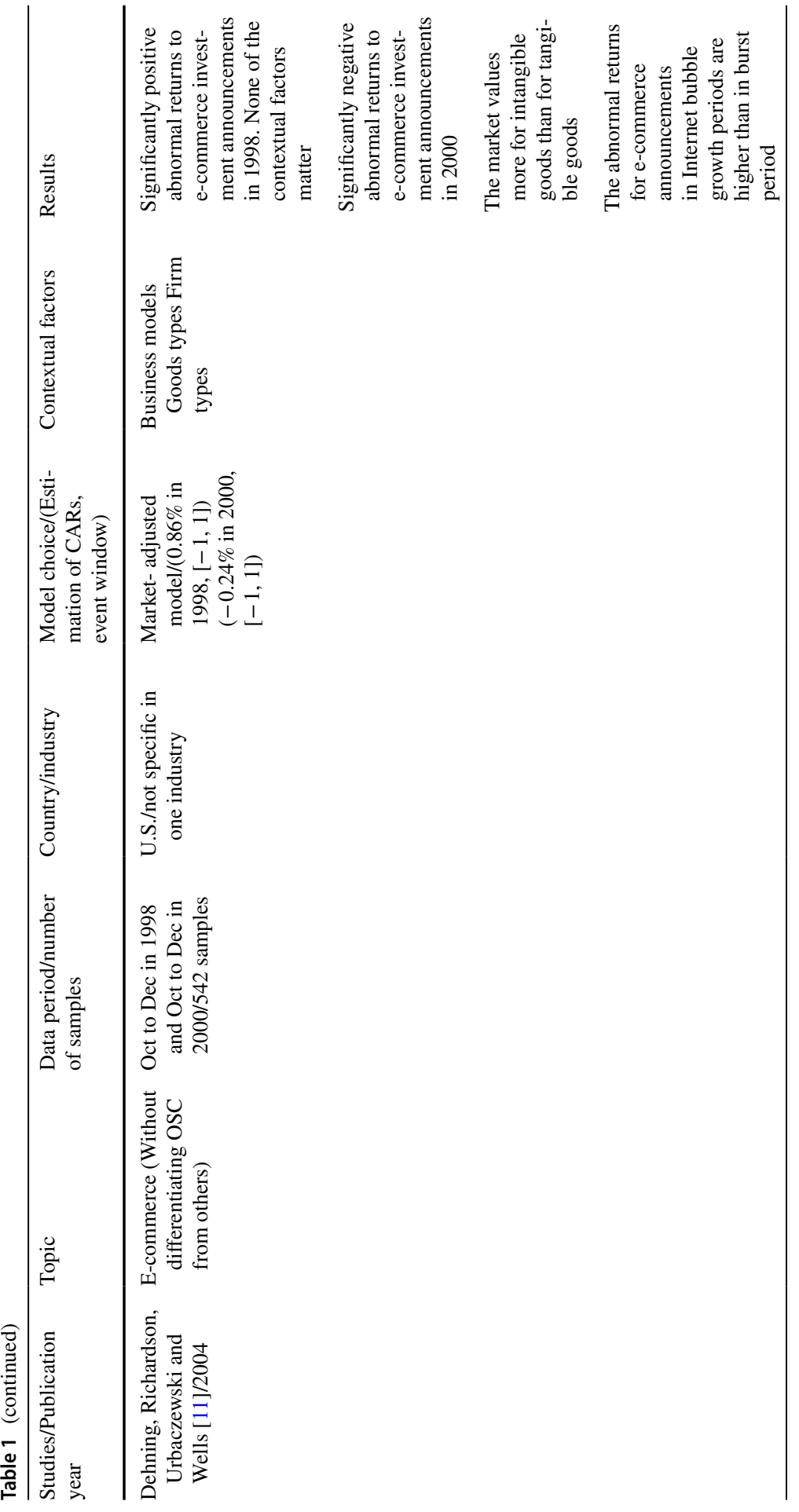




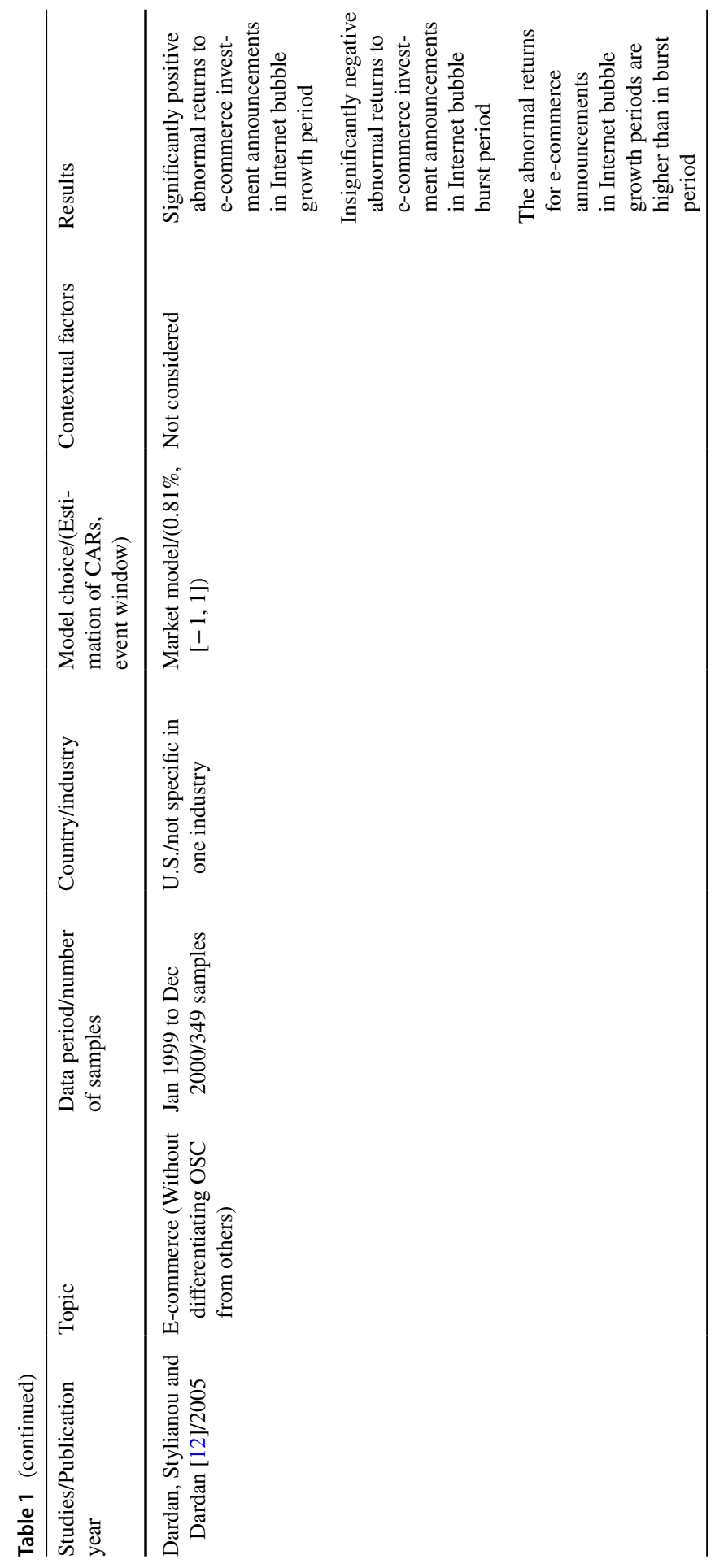




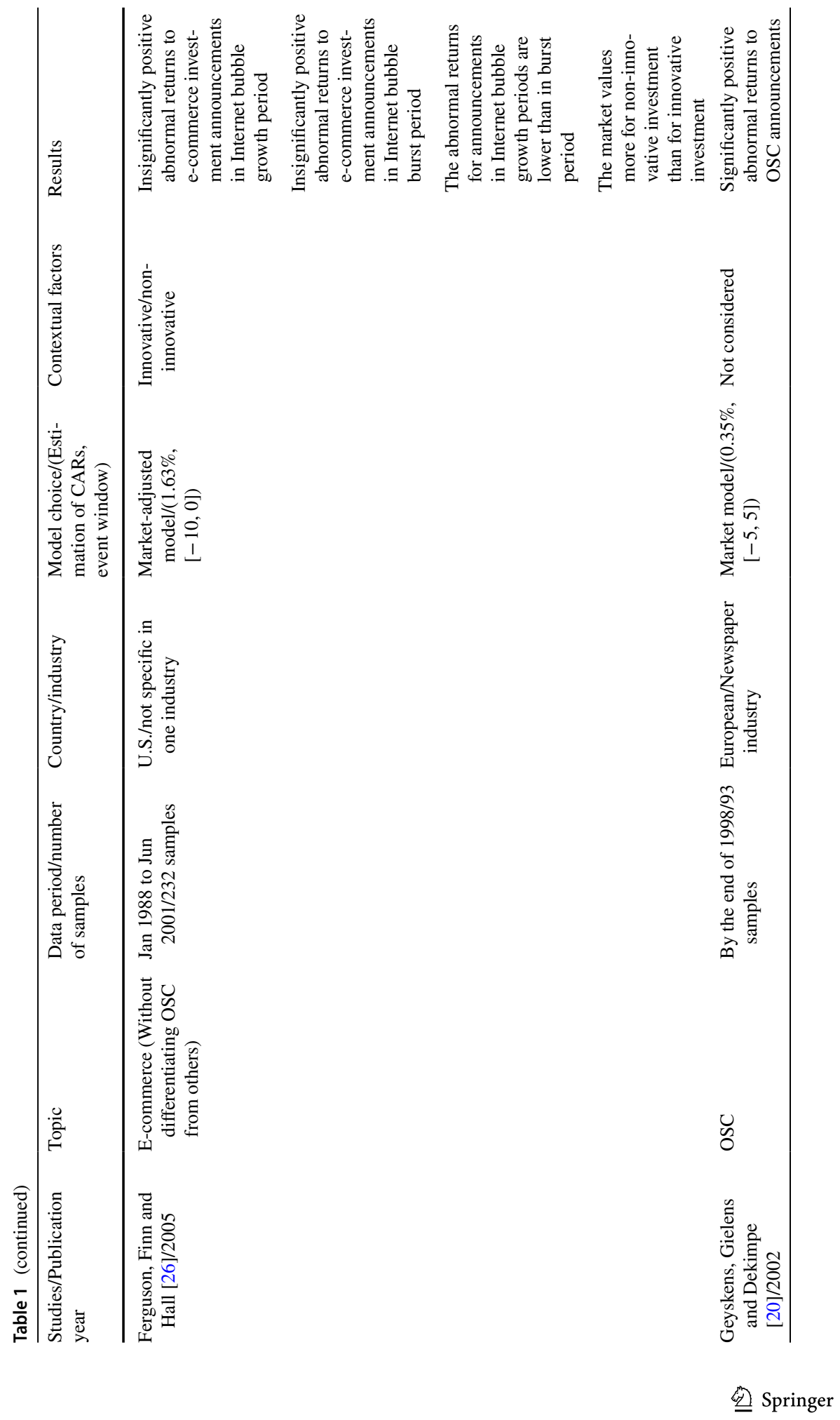




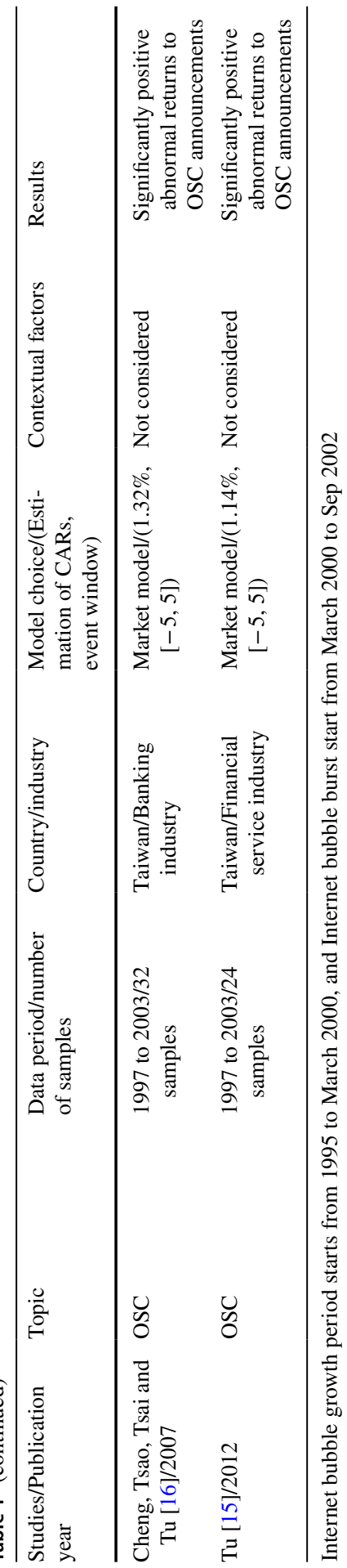




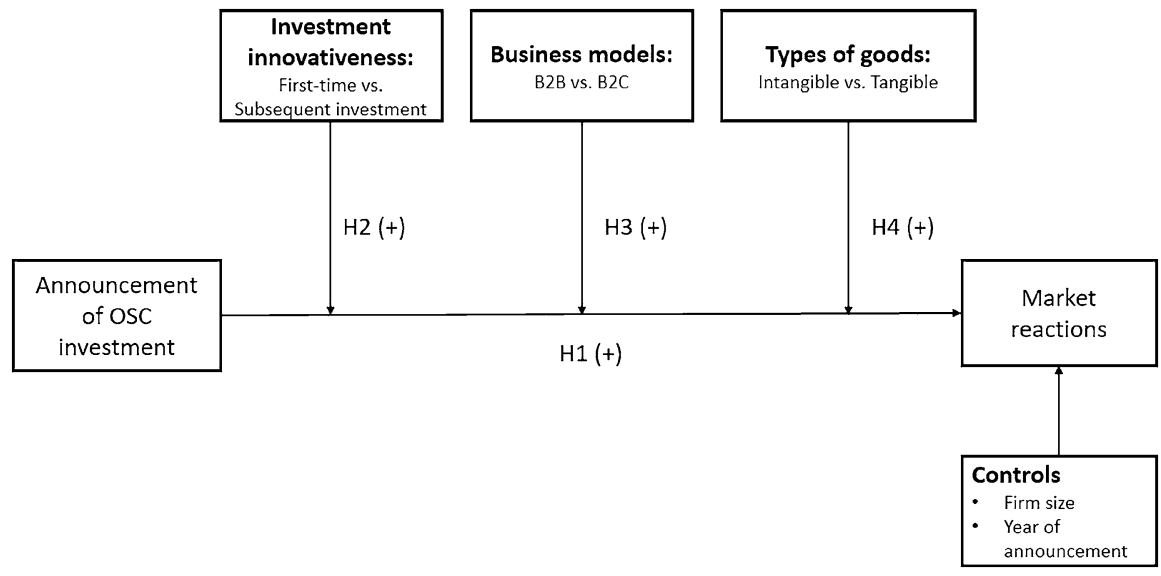

Fig. 2 Research Model

\section{Research model and hypotheses}

Based on the literature review, we propose our research model, as depicted in Fig. 2. We posit that a firm's OSC investment announcement affects the market value of the firm. In addition, we postulate that the three contextual factors of OSC investment, namely investment innovativeness, business model, and the type of goods sold, may moderate the relationship between a firm's OSC investment announcement and the market value of the firm.

\subsection{Market reaction to announcements of OSC investment}

E-commerce with OSC is believed to provide firms with various benefits, which can generate positive attitudes from investors. First, the announcements of OSC investment are interpreted by investors as indicating that firms can facilitate a convenient purchase process for customers by directly establishing links with their customers, thus reducing customers' shopping costs and improving their satisfaction, which in turn enhances firm performance [e.g. 31]. Second, an OSC investment announcement also signals that firms have greater ability to reduce their transaction cost [32] by allowing customers to place orders online [33]. Third, OSC provides firms with flexibility to manage their inventory to improve their service levels to customers. Having both OSC and physical stores, firms are allowed to share inventory through these multi-channels at the distribution center level, the retail store level, or both, thereby facilitating order fulfillment through both the retail network and the OSC [6]. By pooling inventory across channels, traditional retailers with OSCs are better positioned to reap the benefits of improved efficiency and service levels [34]. These benefits suggest that firms announcing OSC investment are likely to realize significant strategic and operational advantages in the future, and lead to a recognition that OSC investment can result in enhanced market evaluation. 
In addition, the benefit of OSC is not necessarily limited to a firm and its customers. A firm's OSC can also improve the efficiency of its suppliers along the supply chain and further improve the entire supply chain performance [35]. For instance, prior studies have documented that e-commerce can facilitate supply chain integration [36] and improve supply chain relationships [37]. Thus, we speculate that investors would realize these benefits and react positively to a firm's OSC investment announcement, and we hypothesize the following:

H1 A firm's OSC investment announcement results in positive market reactions.

\subsection{Contextual factors influencing market value through OSC investment}

\subsubsection{Investment innovativeness}

In this study, investment innovativeness is classified into radical and incremental innovation. Radical innovation investment indicates firms' investment in OSC for the first time, bringing about a radical change to their business [38, 39]: when a firm decides to invest in a specific IT for the first time, it is a radical innovative investment to the firm because it may change the existing working practices and induce innovation. Incremental innovation investment is that firms just make subsequent investment to their existing OSC, for example, redesigning or adding additional functions [39, 40]: when a firm makes subsequent investment (i.e. upgrading the existing IT) in the same IT, it is an incremental innovative investment [39, 40]. Prior studies argue that when an IT is employed for the first time, it will enhance intraorganizational efficiency and effectiveness, thereby affecting the firm's market value [30]. In addition, the first-time implementation of a particular IT and the subsequent investment in the same technology may draw investors' attention differently [19]. Therefore, we propose that these two types of investment elicit different levels of market reactions.

When a firm makes its investment in OSC for the first time, it sends investors a signal that it has launched a radical innovation and begun to acquire a large amount of resources to build capabilities through virtual channel. Consistent with the signaling hypothesis [41], the announcement of OSC investment is a means for a firm to convey favorable private information to investors. Such information impresses investors that a firm has in place an innovative management team leveraging new technologies to exploit growing online markets [6]. If a firm invests and announces its OSC for the first time, it may come as a shock and attract the attention of investors to see how these investments will affect the performance or productivity of the firm [19]. Consequently, such an announcement will have a greater surprise effect, and therefore, lead to larger market reactions [42]. On the contrary, a subsequent investment of OSC may not draw as much attention as the first-time investment does. Investors often foresee subsequent investment in the same IT of a firm, therefore reacting less to it because of the smaller surprise it represents.

In addition, studies have found that radical innovation contributes to firm performance more than incremental innovation [43]. From an organizational perspective, 
radical innovation has the potential to disrupt the market positions of incumbents and set up a new platform to thrive in new markets [44], thus generating more benefits to firms. In addition, a subsequent investment is often intended to maintain or upgrade the existing IT, which may just offer limited additional resources and capabilities to the focal firm. Therefore, we posit that, compared with the firsttime investment, although a subsequent OSC investment announcement still sends a signal that the firm is acquiring value and resources, investors may value such an investment less than the first-time one. This leads to the following hypothesis:

H2 The market reaction to a first-time OSC investment announcement will be more positive than that to a subsequent OSC investment announcement.

\subsubsection{Business model}

Prior e-commerce studies have argued that B2B and B2C have different effects on market value $[10,11]$ because they are quite distinct in several ways [45] such as in regard to customer relationship management [46] and security and privacy policies [47]. Research has found that the perceived customer value in B2B and B2C is different [48]. In addition, B2B e-commerce is often regarded as more profitable than $\mathrm{B} 2 \mathrm{C}$ [49]. It is evident that one of the key issues blocking the development of B2C e-commerce is a lack of B2B infrastructure [50], which can integrate a firm with its suppliers, financial institutions, and distributors [11], thus making the business processes seamless and the operations more efficient and effective.

In addition, evidence shows that the potential market sizes of $\mathrm{B} 2 \mathrm{~B}$ and $\mathrm{B} 2 \mathrm{C}$ are not equal [4]. It is estimated that by 2021, the B2B e-commerce market would be worth $\$ 1.8$ trillion, which will be more than twice the size of the $\mathrm{B} 2 \mathrm{C}$ e-commerce market in the U.S., and it will become bigger in the future [51]. Similarly, it is also estimated that B2B e-commerce in Europe will be twice as large as B2C e-commerce in terms of sales, which will prove a huge unrealized potential for European SMEs [52]. B2B sales in China reached $¥ 16.7$ trillion in 2016, whereas B2C sales were only $¥ 5.3$ trillion [53]. Therefore, by investing in OSC, B2B firms may generate more room for further growth and greater value than B2C firms, thereby leading to higher market value.

Moreover, B2C OSC investments are considered to be riskier than B2B ones. B2C applications need more exploratory effort to build relationships between a firm and its numerous individual consumers, where a common application of B2B initiatives, especially private trading exchanges, only exploits existing relationships between business partners [14]. Even though retailers are often adopting the OSC B2C business model to broaden their markets, retaining customers is also a crucial issue [54], which will involve more customer-relationship management cost than before. Therefore, when providing OSC, it is more difficult for firms to satisfy the personalized needs of numerous individual consumers in B2C applications than in B2B because the number of customers in the former is far larger than in the latter. The cost of customer relationship management will be higher for B2C firms than for B2B firms, which may lower the performance of B2C firms [46]. Therefore, investors may value a B2B OSC higher than a $\mathrm{B} 2 \mathrm{C}$ one. Thus, we propose the following hypothesis: 
H3 The market reaction to the investment announcements of $\mathrm{B} 2 \mathrm{~B}$ OSC will be more positive than that to the investment announcements of $\mathrm{B} 2 \mathrm{C}$ one.

\subsubsection{Goods type}

The types of goods sold through OSC may also influence the market reaction because of the different cost structure. Goods can generally be categorized into tangible and intangible goods (service, which is intangible in nature, belongs to the intangible goods type in this study). From a strategic perspective, intangible goods have an inherent advantage over tangible goods owing to their much lower marginal cost and higher marginal profits [55]. By implementing OSC, the near-zero cost of production for intangible goods leads to higher profits. In addition, the delivery of intangible goods is not subject to physical limitations and time constraints [10], thus reducing the delivery cost and increasing sales revenue which, in turn, generates more profit for the companies.

Moreover, the shopping experience differs for tangible and intangible goods through OSC. It is difficult for customers to 'experience' tangible goods before purchasing them in an e-commerce context, which decreases customers' perceived value and lowers their intention to buy [56]. Furthermore, when a customer decides to return the purchased tangible goods, it takes higher effort and cost (i.e. delivery costs) than when dealing with intangible goods, which may further decrease customer satisfaction [57]. Given the above argument, we posit that offering intangible goods appears to be more profitable than offering tangible goods through OSC. Thus, investors may have more positive attitudes to OSC announcements involving intangible goods than those involving tangible goods. Therefore, we propose the following hypothesis:

H4 The market reaction to OSC announcements involving intangible goods will be more positive than that to OSC announcements involving tangible goods.

\section{Methodology}

\subsection{Event study}

Managers have incentives and strategies to manipulate accounting profit because it is a key indicator that reflects financial performance of a firm [58]. However, it is very difficult for managers to manipulate the stock prices of their firms [23]. In addition, because stockholders are the most important stakeholders in for-profit businesses, maximizing market value is the basic and primary goal for them [59]. Event study is a statistical approach to assess whether the market value of a firm, represented by its stock price, will be influenced by an exogenous or endogenous event [23]. It draws on the efficient market hypothesis (EMH) that financial markets are able to process publicly available information to assess the impact of a firm's financial performance and adjust expectations for its future achievements [41]. When a firm announces information on its activities that may impact its future earnings, the stock price may 
react to such information and change to reflect the current assessment of the market value. The strength of the method lies in the fact that "it captures the overall assessment by a large number of investors of the discounted value of current and future firm performance attributable to individual events, which is reflected in the stock price and the market value of the firm" [10]. Thus, we use the event study to test our research model and hypotheses.

\subsection{Data collection and screening}

The event in this study is defined as a public announcement of a firm's OSC investment. We performed a full-text search of the announcements made by firms between October 2002 and September 2007 (the search was ended in September because the capital market experienced a dramatic drop due to the subprime crisis from October 2007 onward) [60]. We used the global news provider Factiva to search the two leading media outlets, namely PRNewswire and BusinessWire, based on the keywords "purchase, buy, shopping" with "Nasdaq, NYSE, and AMEX," in which the texts that contained at least one of the following words: "online sales channel," "e-channel," "electronic channel," "electronic commerce," "e-commerce," "electronic business," "e-business," "mobile commerce," "m-commerce," and "online channel." Such broader terms were used to make sure that we would not miss any OSC investment announcements, including the implicit ones, in the first stage for further screening. The Factiva search generated an initial sample of 2,531 announcements.

A consensus procedure in line with previous research [e.g. 10, 61] was employed to determine the relevance of the announcements to this study. The first and third authors participated in configuring the content of each announcement and in deciding whether the announcement was relevant. If discrepancies were found, they then undertook discussion with another author to determine the classification of the announcement. In addition, some announcements involving multiple firms were carefully examined to identify the firms that actually invest in OSC. For example, both ATG (Nasdaq: ARTG) and OfficeMax (NYSE: OMX) announced on February 13, 2006 that OfficeMax would leverage ATG's e-commerce solution to provide online shopping to customers. In this case, OfficeMax was identified as the firm that made the OSC investment. Moreover, announcements of general news and without firm-specific events were excluded. Finally, following some prior study [14], we dropped the firms with multiple OSC announcements within an 11-day window (the length of event window in our main model) around the event date. As a result, we identified 85 announcements of such events; these were filtered in the presence of confounding events such as overlapping announcements regarding dividends, earnings, mergers and acquisitions, and executives change [23]. To further ensure that the announcements satisfied the EMH, we checked them against the following criteria: (1) Dropped newly listed firms that only have a trading history of less than 210 days prior to the event date, because trading history is necessary to estimate the market reaction; (2) Eliminated firms with an average stock price less than $\$ 1$, because the price changes in these companies tend to be unrepresentative of the broader market; (3) Removed firms with average daily stock trading less than 50,000 shares, 
because such a small trading volume represents questionable market efficiency and low liquidity of these firms' stocks. After data cleaning, we finally selected 69 OSC announcements for further analysis. Two examples of the announcements are: Callaway Golf Company (NYSE:ELY) announced its new e-commerce sites for online shopping on November 8th 2006; Skyworks Solutions, Inc. (NASDAQ:SWKS) announced its e-commerce initiative for order processing on April 19th 2005. The detailed announcements of these two examples are provided in Appendix Table 8. The analysis procedure is listed in Table 2. The demographic information of our samples is displayed in Table 3.

\subsection{Coding}

Content analysis was performed to obtain the values of the contextual factors for hypothesis testing. Content analysis has increasingly been used in IS research to classify the content of documents or textual data [62]. The first and third authors first read through the announcements and coded each contextual factor individually. Then, they checked the test-retest reliability by recoding the announcements about a week after the initial coding. The test-retest coding shows that the results in the two rounds are very similar (by over 90\%). Thereafter, the first and third authors compared their results and discussed any differing results to reach a consensus. Examples of coding are shown in Appendix Table 9.

\subsubsection{Investment innovativeness}

We classify OSC announcements as "first-time investment" to indicate radical innovative investments, and "subsequent investment" to indicate incremental innovative investments, according to similar criteria in prior studies [19]. We used keywords such as "open/launch/implementation a new website/online store", "add/ design a new service to online store/websites", and "first/initial launch of a website/ online store" to identify first-time investment in OSC announcements. In contrast, keywords like "the second/third generation/version of online website", "restart/ relaunch/reopen e-commerce/online channel", and "merge websites together" were used to identify subsequent investment announcements. Finally, we obtained 32 announcements of first-time OSC investment and 37 of subsequent ones.

\subsubsection{Business models}

The e-commerce business model was classified into B2B and B2C, which is the same as that in Subramani and Walden [10]. The announcements were treated as B2B if they involve business agreements between firms (these agreements usually consolidated settlements of payments over multiple transactions) and B2C if they involve transactions between a firm and its individual consumers (payments are 


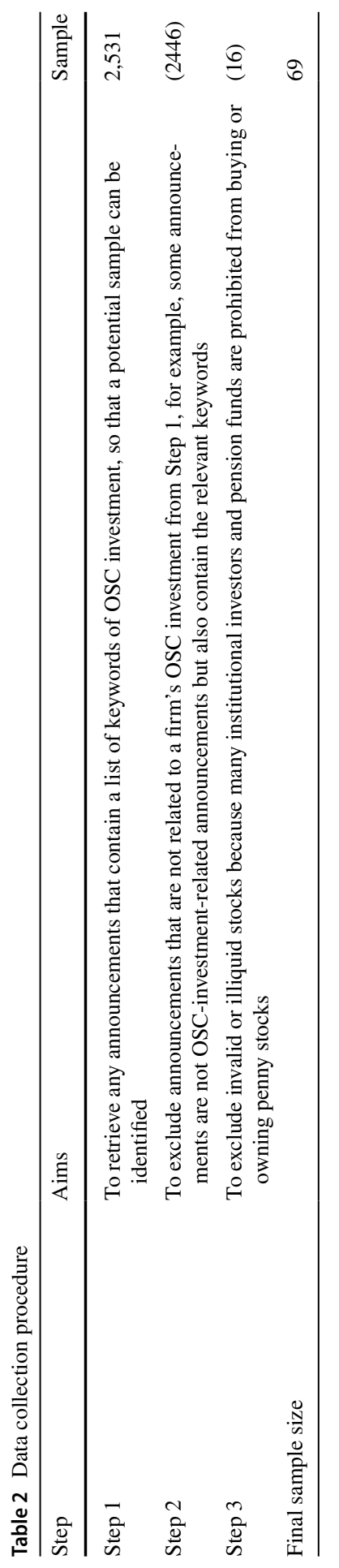


Table 3 Distribution of announcements over time and by industry

\begin{tabular}{llcclc}
\hline Year & Manufacturing & Service & Retail & Others & Full samples \\
\hline 2002 & 7 & 1 & 4 & 0 & 12 \\
2003 & 3 & 5 & 3 & 0 & 11 \\
2004 & 3 & 7 & 3 & 0 & 13 \\
2005 & 3 & 5 & 1 & 0 & 9 \\
2006 & 2 & 3 & 3 & 2 & 10 \\
2007 & 1 & 9 & 3 & 1 & 14 \\
Total & 19 & 30 & 17 & 3 & 69 \\
\hline
\end{tabular}

usually linked to individuals). The analysis of the 69 announcements resulted in the classification of 24 as $\mathrm{B} 2 \mathrm{~B}$ and 45 as $\mathrm{B} 2 \mathrm{C}$.

\subsubsection{Goods types}

Goods were classified as tangible or intangible goods, according to goods type. We classified announcements involving services that are available online to use or download (e.g. digital music, online trading, and software) as intangible goods. The announcements involving goods that can only be physically delivered (e.g. sports merchandise, clothes or books) are classified as tangible goods [10]. The analysis resulted in 34 announcements involving tangible goods and 35 announcements involving intangible goods.

\subsection{Estimation method}

We collected the stock prices based on MacKinlay's [63] suggestions. The Center for Research in Security Prices (CRSP) provides daily stock price data for all listed companies trading on the United States stock market. Abnormal returns and test statistics were calculated using Eventus, a software package that interfaces between the SAS and CRSP databases to compute abnormal returns for specified event windows using specified models.

First, to calculate the effect of an event, it is necessary to estimate the stock return under the situation when the event had not occurred. We ran a regression of the return of the stock against the return of a market index to control the overall market effects. The estimated coefficients from the above regression are used to calculate the predicted value of the stock over the time window in which the stock price is adjusted. This yields the Eq. (1).

$$
R_{x, t}=\alpha+\beta_{x} R_{m, t}+\in_{x, t},
$$

$R_{x, t}$ is the return of stock $x$ on day $t: R_{x, t}=\left(\right.$ Price $_{x, t}-$ Price $\left._{x, t-1}\right) /$ Price $_{x, t-1}$. Similarly, $R_{m, t}$ stands for the market return on day $t$, that is, the average of returns for all listed firms represented by a stock market index. We used the S\&P 500 as the market 
index. The S\&P 500 is a capitalization-weighted index based on a broad cross-section of the market and it has been commonly employed in prior event studies [10]. The $\in_{x, t}$ is a random error term for stock $x$ on day $t$ with the usual ordinary least squares (OLS) properties, $\alpha$ is the intercept, and $\beta_{x}$ is a parameter used to measure the sensitivity of $R_{x, t}$ on $R_{m, t}$.

To estimate the abnormal returns, we first determined the normal returns. The period for estimating normal returns typically ranges from 100 to 300 days for event studies $[17,63]$. To facilitate the comparison with prior studies, this study used a time period of 200 days ( -205 to -6 ) before the event to estimate the expected return [e.g. $29,64]$. We conducted all analysis for two different event windows, a three-day window $[-1,+1]$ and an 11-day window $[-5,+5][13]$; that is, one comparatively shorter event window and another relatively longer one [14]. The shorter window is likely to more accurately reflect the information content of the OSC announcements themselves. The longer window is chosen because the information regarding OSC announcements might be leaked in advance of the actual event announcement, as well as to enable comparison of our results with those from prior research [10]. In addition, previous theoretical event study research emphasized that the dividend element, of which the influence of dividend was reflected in the stock price change in ex-dividend date, should be considered [65].

We used the coefficient estimates from Eq. (1) to predict the expected return over $t=[-1,1]$ and $t=[-5,5]$ event windows. The OLS market model, the most commonly used one [e.g. 10, 16], was applied in this study to estimate the abnormal returns (AR) for the stock of firm $x$ on day $t$ :

$$
\mathrm{AR}_{x, t}=R_{x, t}-\left(\alpha+\beta_{x} R_{m, t}\right)
$$

The coefficients $\alpha$ and $\beta_{x}$ are the estimates of the true parameters obtained via OLS. The abnormal returns are simply the prediction errors of the model over the event window. Notice that AR are abnormal returns: they are returns over those predicted by the general trend of the market on each day. The assumptions of the methodology are that the abnormal returns are the result of the announcement but not some other random events occurring on the same day.

Like prior studies [17, 18], we calculated the cumulative abnormal returns (CARs) over the event window as follows:

$$
\mathrm{CAR}_{x, j}=\sum_{i=-j}^{j} \mathrm{AR}_{x, i}
$$

where $\mathrm{CAR}_{x, j}$ is the cumulative abnormal returns of stock $x$ on an event window $j$. In addition, the normality of the abnormal returns of each firm has been checked using SPSS software. While the result rejects that they fit the normal distribution, we believed it is not a critical issue. Some researchers have argued that the degree of non-normality in daily New York Stock Exchange security abnormal returns does not represent a serious problem for a correct test specification [66]. 


\subsection{Hypothesis testing}

We first calculated the mean CARs of OSC investment for both the three-day window and 11-day window to test $\mathrm{H} 1$. The Patell $\mathrm{Z}$ test was run to estimate the mean CARs and test whether they differ from 0 [67]. A non-parameter test was also conducted because the abnormal returns of the sample firms are not normally distributed [68].

To statistically test $\mathrm{H} 2$ to $\mathrm{H} 4$, we validated our hypotheses by cross-sectional OLS regression. The model uses $\mathrm{CAR}$ as a dependent variable and incorporates the three contextual factors. Like prior studies [18], we controlled the year of announcement as the year-specific effect. In addition, previous studies have found that firm size could influence a change in stock price [e.g. 64, 69]. Therefore, firm size was included in the model as another control variable. The regression equation is as follows:

$$
\begin{aligned}
\mathrm{CAR}_{1,2}= & \beta_{1}+\beta_{2} * \mathrm{FT}+\beta_{3} * B 2 B+\beta_{4} * \text { Intangible } \\
& +\beta_{5} * \sum \text { Year }+\beta_{6} * \text { Industry }+\beta_{7} * \text { Size }+\beta_{8} * \mathrm{IT}+\epsilon
\end{aligned}
$$

where $\mathrm{CAR}_{1}$ indicates the CARs in three days and $\mathrm{CAR}_{2}$ indicates the CARs in 11 days; "FT" is a dummy variable to represent "first-time" with 1 for innovative investment and 0 for non-innovative investment. Likewise, "B2B" is a dummy variable with 1 for B2B and 0 for B2C. "Intangible" is a dummy variable with 1 for intangible goods and 0 for tangible goods.

In addition to the hypothesized factors, we include several control variables in our research. First, to control the year-specific effect, we added five dummy variables that represents the year of the e-commerce announcement and other years in 2002-2007; We then control the industry effect by adding three dummy variables that representing the manufacturing, service, retail, and other industries; and an IT-related dummy captures the characteristics of a firm with 1 for IT company and 0 otherwise. Finally, firm size is controlled to alleviate its influences with the natural log of the firm's total assets at the end of the quarter preceding the OSC announcement (the firms' total assets are collected from Compustat database); " $\in$ " is a disturbance term with the usual OLS properties.

\section{Results}

\subsection{The direct effect of OSC announcements on the market value}

The results of the Patell $\mathrm{Z}$ test, as shown in Table 4, show significant positive abnormal returns $(\mathrm{CAR}=1.52 \%, p<0.05)$ for a three-day window together with a significant non-parameter test of generalized sign $\mathrm{Z}(t=1.746)$, while the abnormal returns for an 11-day window becomes insignificant (CAR $=-0.62 \%, p=0.256)$. Although the market reaction may tend to be flat in a longer period, there is a significant fluctuation in a short period, indicating the stock market indeed values OSC announcement. Therefore, $\mathrm{H} 1$ is still supported. The significant results are consistent with previous OSC studies and provide additional evidence to the theory that shareholders place additional value on firms that invest in OSCs with an investigation in a 
Table 4 CARs, Patell Z-test, and generalized sign Z test for OSC announcements

\begin{tabular}{lcllc}
\hline Time window & CARs $(\%)$ & Patell Z & $\%$ positive & Generalized sign Z \\
\hline$(-1,1)$ & 1.52 & $2.259^{* *}$ & 58.0 & $1.746^{*}$ \\
$(-5,5)$ & -0.62 & 0.004 & 46.4 & -0.183 \\
\hline
\end{tabular}

$N=69 ; * * * p<0.01, * * p<0.05, * p<0.1$

Table 5 Standardized regression coefficients for $(-1,1)$ and $(-5$, 5) event window $(N=69)$

\begin{tabular}{lcc}
\hline & CARs for $(-1,1)$ & CARs for $(-5,5)$ \\
\hline Model F & $1.701^{*}$ & $1.982^{* *}$ \\
$\mathrm{R}^{2}$ & $28.7 \%$ & $31.9 \%$ \\
Adjusted $\mathrm{R}^{2}$ & $11.8 \%$ & $15.8 \%$ \\
Independent variable & & \\
Constant & $0.108^{* *}$ & -0.029 \\
FT(first-time) & 0.079 & $0.361^{* * *}$ \\
B2B & $0.298^{* *}$ & $0.267 * *$ \\
Intangible & -0.022 & 0.013 \\
Size (Log (assets)) & $-0.315^{* *}$ & -0.157 \\
Year 2003 & -0.168 & -0.216 \\
Year 2004 & -0.277 & -0.051 \\
Year 2005 & $-0.270^{*}$ & -0.095 \\
Year 2006 & -0.197 & 0.037 \\
Year 2007 & $-0.353^{*}$ & -0.148 \\
Manufacturing & -0.181 & 0.079 \\
Retail & -0.083 & 0.209 \\
Service & -0.116 & 0.292 \\
IT & -0.017 & 0.067 \\
\hline
\end{tabular}

$N=69 ; * * * p<0.01, * * p<0.05, * p<0.1$

stable market. Moreover, if we go back to check the fifth and last columns in Table 1 to compare our study with the previous ones, we can find the magnitude of CARs of them is similar, indicating that the choice of the event windows in our study is appropriate.

\subsection{The contextual factors related to OSC announcements on the market value}

The results of the cross-sectional analysis described in Eq. (4) are shown in Table 5. For the investment innovativeness, the coefficients of first-time OSC investment announcements are positive in both the three-day and 11-day windows, and significant in the 11-day window. One explanation for the insignificant results for CARs during the three-day window is that investors need a relative longer period to differentiate the value of first-time investment and subsequent investment in OSC because 
numerous e-commerce crushed within the Internet bubble burst period. The results indicate that compared with subsequent OSC investment announcements, first-time OSC investment announcements are more favorably evaluated, which supports $\mathrm{H} 2$. In regard to the different effects of the business models, B2B is significantly associated with positive market reaction in both the three-day and 11-day windows, thereby supporting $\mathrm{H} 3$. The results indicate that B2B OSC applications receive a more favorable evaluation from investors than $\mathrm{B} 2 \mathrm{C}$ ones. However, the coefficients for OSC involving different types of goods are not statistically distinguishable from zero either in the three-day or 11-day windows, indicating that the stock market does not significantly differentiate between a firm's OSC announcements involving intangible and tangible goods. Therefore, $\mathrm{H} 4$ is not supported.

In regard to the control variables, the firm size is negatively related with CARs in both the three-day and 11-day windows, and the effect in the three-day window is significant. This is consistent with the findings of prior studies in that compared with larger firms, relatively small-sized firms are more favorably evaluated in terms of their IT investment in the market [e.g. 27]. As the IT-related and industry-related controls are not significant, the results indicate that there are no significant differences in the investment in OSC across companies and industries. In addition, we find that there are significant negative CARs for the OSC investment announcements made in 2007. Although this indicates that the market expectation of OSC investment dropped in the subsequent years, the result could be further explored with more samples.

\subsection{Robustness check and additional analysis}

\subsubsection{Robustness check}

According to prior event studies, the stock market may react to announcements with extremely high or low abnormal returns [18]. Such kinds of abnormal returns, identified as outliers, may contaminate the results. Using Cook's distance analysis [70], we identified some outliers in our dataset. By winsorizing these outliers to their nearest value, we tested whether the CARs are still significantly higher than 0 . The results are consistent with our main analysis, thereby suggesting the robustness of our results.

In addition, prior event studies adopt different estimation windows to assess normal returns, which could affect the estimation of abnormal returns [17]. Therefore, we further examined the abnormal returns with various alternative estimation windows: -255 to -10 (for three-day event window, $\mathrm{CARs}=1.37 \%, p<0.05$; for 11-day event window, CARs $=-0.73 \%, p=0.50$ ), -250 to -30 (for three-day event window, CARs $=1.36 \%, p<0.05$; for 11 -day event window, CARs $=-0.65 \%$, $p=0.55$ ), -210 to -120 (for three-day event window, CARs $=1.34 \%, p<0.1$; for 11-day event window, CARs $=-0.42 \%, p=0.71$ ), -120 to -5 (for three-day event window, $\mathrm{CARs}=1.37 \%, p<0.05$; for 11-day event window, CARs $=-0.54 \%$, $p=0.63$ ), and -105 to -5 (for three-day event window, $\mathrm{CARs}=1.37 \%, p<0.05$; for 11-day event window, CARs $=-0.75 \%, p=0.51$ ), which have been used by prior 
Table 6 CARs and Patell $\mathrm{Z}$ test for OSC announcement within April 2001 to September 2002

\begin{tabular}{|c|c|c|c|c|}
\hline \multirow{2}{*}{$\begin{array}{l}\text { Period } \\
\text { Time window }\end{array}$} & \multicolumn{2}{|c|}{$\begin{array}{l}2002.10 \text { to } 2007.09 \\
(N=69)\end{array}$} & \multicolumn{2}{|c|}{$\begin{array}{l}2001.04 \text { to } 2002.09 \\
(N=88)\end{array}$} \\
\hline & CARs (\%) & Patell Z & CARs (\%) & Patell Z \\
\hline$(-1,1)$ & 1.52 & $2.259 * *$ & -0.85 & -1.042 \\
\hline$(-5,5)$ & -0.62 & 0.004 & -2.95 & $-1.784^{*}$ \\
\hline
\end{tabular}

event studies [e.g. 71, 72]. The results are also consistent with those of our main analysis, thus supporting the data from the latter.

Third, prior studies have pointed out that the event study methodology, especially the estimation of abnormal returns, is sensitive to different models [11]. Therefore, we further tested our model using other estimation models and got the similar results, $\beta=1.36 \%, p<0.05$ from market-adjusted model, $\beta=1.66 \%, p<0.05$ from the Fama-French Three Factor Model, and $\beta=1.37 \%, p<0.05$ from the Four Factor Model in three-day event window. These results are consistent with the findings using market model in our main study, which indicates the robustness of its results.

Fourth, while the stock index begun to stabilize since the mid of 2002 and the Internet bubble burst is usually believed to last till September 2002, as shown in Fig. 1, the unknown lasting effect may contaminate our main results. Therefore, we further exclude those announcements between October 2002 and August 2003 to alleviate such concerns. The results show that the CARs in three-day event window is $1.31 \%, p<0.1$, in 11 -day event window is $1.17 \%, p>0.1$. In addition, for other estimation windows used in the above robustness check, the results are consistent, for example, -255 to -10 (for three-day event window, $\mathrm{CARs}=1.17 \%, p<0.05$; for 11-day event window, CARs $=-0.42 \%, p>0.1$ ), -250 to -30 (for three-day event window, CARs $=1.18 \%, p<0.05$; for 11 -day event window, CARs $=-0.41 \%$, $p>0.1$ ), -210 to -120 (for three-day event window, $\mathrm{CARs}=1.12 \%, p<0.05$; for 11-day event window, CARs $=-0.65 \%, p>0.1$ ), -120 to -5 (for three-day event window, $\mathrm{CARs}=1.18 \%, p<0.1$; for 11 -day event window, CARs $=-0.20 \%$, $p>0.1$ ), and -105 to -5 (for three-day event window, CARs $=1.18 \%, p<0.1$; for 11-day event window, CARs $=-0.35 \%, p>0.1)$. Thus, the lasting effect is not a serious problem.

\subsubsection{Additional analysis}

In order to verify the influence of market environment, we collected data from April 2001 to September 2002, a period of unhealthy market conditions where the Internet bubble burst. Following the same process as described in Sect. 4.2, we identified 88 investment announcements related with OSC and calculated the CARs for both three-day and 11-day windows. As shown in Table 6, the CARs in both the three-day and 11-day windows are negative and the coefficient in 11-day window is significant, suggesting that the market does not (even negatively) value OSC in that period. Considering the positive CARs results of the main study, we explain that during the 
bubble burst period, investors generate negative expectations towards the Internetrelated announcements. Even though the true value of OSC investment exists, investors were still afraid of the failures of dotcom companies which may cause capital loss and then reacted negatively. Another interesting phenomenon is that the negative CARs in the three-day window are not different from 0 . This result suggests that in the Internet bubble burst period, investors are not totally negative, although their reaction still does not reflect the true value of OSC. The additional analysis indicates that data from an unstable period may not tell the true story. Therefore, a healthy market environment is necessary when using event study methodology to assess the market value of an event.

\section{Discussion}

This study investigates the economic value of OSC from the perspective of the stock market. Specifically, we scrutinize the market value of OSC investment announcements from the perspective of the stock market in a relatively stable market environment. The results are summarized in Table 7; most of our hypotheses are supported, except $\mathrm{H} 4$.

Contrary to the findings of prior studies that the goods type is a significant predictor of the differences in the market reaction to e-commerce initiatives $[10,11]$, we fail to find distinct effects of goods type on the market reaction, i.e. investors do not perceive differently the potential values of OSC investment announcements involving different types of goods. One possible reason is that with the increasingly efficient delivery and product return process, shopping for tangible goods online is almost as convenient and easy as purchasing intangible goods. In addition, the availability of more features embedded in the e-commerce environment, such as electronic fitting rooms, can improve the online shopping experience for tangible goods. Firms can sell tangible goods in almost the same way as they sell intangible goods over the Internet; the disadvantages of selling tangible goods online seem to no longer pose a problem. Therefore, the differences between different goods types are also decreasing.

\subsection{Theoretical implications}

This study has several theoretical implications. First, it contributes to the existing e-commerce literature by focusing on the market value of OSC. Although the impact of e-commerce investment on firm performance has long been discussed by IS scholars, most relevant studies have not differentiated whether the e-commerce investment actually has or has not OSC. From their studies, we infer that they might have included the firms both with and without OSC, which leads to the mixed results. Apart from case studies and extensive anecdotal evidence, a new branch of studies has emerged recently to empirically investigate the market value of OSC, in a single industry; these include Geyskens et al. [20] in the newspaper industry, and Cheng et al. [16] and Tu [15] in the financial service industry. The valuable insights 


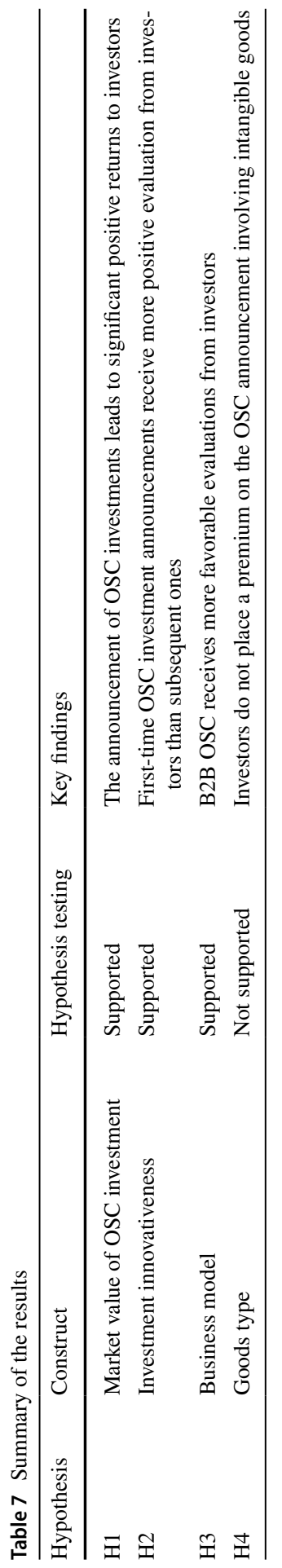


from these studies need to be generalized to a broader range of industries. Our study is one of the few to assess the market value of OSC in the overall stock market with the inclusion of firms from different industries, thereby contributing to the existing body of knowledge.

Second, this study broadens the theoretical knowledge of the economic value of OSC investment by empirically examining the association of contextual factors with market reaction to OSC investment announcements. Although several studies focus on the market reaction to OSC investment $[15,16,20]$, the current study is among the first to examine the contextual factors of OSC investment and to empirically validate their relationship with their economic value. We believe that a more detailed understanding of the effect of OSC must be obtained to guide future research. The investigation of the contextual factors in relation to OSC can also enrich the current literature.

Third, this study further contributes to the event study literature. Because it has been adopted as an effective methodology to assess the economic value of IT investment from the perspective of the stock market, evidence from an extreme market environment may not reflect the true value of information technology investment [11]. This study was conducted in a relatively stable market environment during the post-Internet bubble period, indicating that stable market conditions should be chosen for similar future event studies on corporate activities, i.e. information technology investment announcements.

\subsection{Practical implications}

In addition to the theoretical implications, our study has several practical implications. First, the findings provide preliminary evidence regarding the benefits of OSC investment. By observation, many firms that claim to implement e-commerce only have their contact information available on their websites to facilitate information search or adopt e-commerce as an advertising channel or a customer support channel. Managers of these firms are actually uncertain of whether they should invest in OSC, having witnessed the failures of other companies in this regard. Our results provide assurance to these managers by supporting the expansion of the scope of their businesses in the online context so that the firms can enjoy the benefits of OSC.

Second, the results illustrate that the market values OSC with specific characteristics differently. In regard to investment innovativeness, investors value radical innovative OSC investment (first-time investment) more than incremental innovative ones (subsequent investment). Therefore, it is recommended that managers invest more radically in innovative IT investment in order to gain a first-mover advantage. In addition, managers are strongly suggested to announce their first-time investment in a specific IT, such as cloud computing and blockchain, to generate greater 'surprise' and reap higher benefits as a pioneer, and, in turn, gain competitive advantages [73].

Third, we find that $\mathrm{B} 2 \mathrm{~B}$ OSC applications receive more favorable attitudes from investors than B2C ones. From a managerial perspective, this empirical result highlights the potential benefits of doing business with business. Indeed, we have 
observed a phenomenon wherein many $\mathrm{B} 2 \mathrm{C}$ firms are shifting toward adopting a B2B strategy [74]. Thus, it is reasonable for some B2C firms to expand their business to B2B. However, it does not mean that all B2C firms should completely change to B2B: this decision depends on the position of the firm in the supply chain. For firms facing individual consumers downstream of a supply chain, there is more room to implement B2B with their suppliers.

However, caution should be exercised when generalizing this finding to situations with different external business environments. For example, because of the COVID19 pandemic, the number of e-commerce users in China surged by 100 million and the number of stores on major online retail platforms increased 3.8\% annually; further, online retail sales were 5.15 trillion yuan (about 736.7 billion U.S. dollars) in the first half of 2020, representing an annual increase of 7.3\% [75]. In addition, skyrocketing stock prices of the e-commerce giants, such as Amazon, Alibaba, Meituan, and Tencent, reflect the market perception that the COVID-19 pandemic has forced increasing numbers of consumers to shop online, thus creating new opportunities for B2C firms. Therefore, a better strategy is to develop e-commerce not only upstream but also downstream along the supply chain.

Finally, social media commerce, a type of OSC, has become increasingly popular in the last few years. Indeed, several studies have confirmed the positive relationship between a firm's social commerce capabilities and its performance [76]. The use of advanced information technologies, such as big data analytics and machine learning, could enable managers to take advantage of users' behaviors and reviews to enhance online customer engagement. Therefore, we recommend that managers make innovative investments in social media commerce.

\subsection{Limitations}

This study has some limitations that offer opportunities for future research. First, the event study methodology relies on stock market data, thus excluding private-controlled enterprises which are usually small-and-medium-sized enterprises (SMEs). Because SMEs and large firms are quite distinct from each other [e.g. 77, 78], future studies can verify our results by looking into SMEs using different methods such as case studies and surveys.

Second, the constructs in the research model are limited to available information derived from our sample. We acknowledge that other meaningful constructs may offer a better explanation of the relationship between OSC investment and firm performance. Therefore, our research model needs to be further refined by considering organizational and technological features in order to capture the effects of OSC on economic value in a more detailed manner. Moreover, future studies could concentrate on the new phenomenon of the effect of social media commerce investment and explore its corresponding specific contextual determinants.

Third, the sample size of our study is relatively small compared to other IT investment, although it is a common problem for OSC event study. For example, Cheung et al. [16] use 32 samples during 1997-2003 and Tu [15] only has 24 samples during 
1997 to 2003 in their studies. Future studies should attempt to include public companies in Europe and Mainland China to get larger sample. Both of the markets grow rapidly for it is estimated that Europe will reach 604.87 billion dollars and Mainland China 477 billion dollars [4].

Finally, the data in our study has been collected 10 years ago, which seems old. However, it still has its merits with the following reasons: First, the OSC has not been developed as rapid as people expect. As we mentioned in the introduction, only $60 \%$ of the Fortune 500 have applied OSC till 2018. The statistics of the percentage of online sales to total sales is only $18 \%$, which indicates its limited development [79]; Second, the definition of OSC has not been changed much, although the technology of online sales channel has been incrementally improved in the past decade [e.g. 5, 80]; Third, the US stock market is mature and consistent and the research results on the market reaction in last decades still possess values for the current research and practice [13]. However, a more recent data in future study will bring more updated insights to both academics and practice.

\section{Conclusion}

Although e-commerce has been widely studied, the effects of adopting OSC still warrant attention. This study is one of the first to investigate the market reaction to OSC investment announcements in a relatively stable market environment as well as to explore the key contextual factors of OSC and empirically assess their potential value.

The findings from this study indicate that OSC investment leads to positive abnormal returns for firms. That is, economic value can be accrued from OSC. In addition, the results indicate that investors value innovative OSC investment announcements higher than non-innovative ones. The business model of OSC investment is also relevant because the market values B2B higher than B2C. It should be noted that brand-new information technologies and the ever-changing business environment will further demonstrate strong vitality and resilience of e-commerce. Therefore, the findings of this study will motivate researchers and practitioners to explore novel theoretical and practical implications of e-commerce under new conditions.

\section{Appendix 1}

See Tables 8 and 9. 
Table 8 Two Examples of OSC announcements

CARLSBAD, Calif.-(BUSINESS WIRE)—November 8 2006-Callaway Golf Company (NYSE:ELY) today launched Shop.CallawayGolf.com, an innovative alliance between Callaway Golf and its vast network of authorized U.S. retailers that provides a new level of service, security and convenience to online consumers. This breakthrough online shopping experience links consumers and superior golf retailers by permitting the consumer to place an order through Callaway Golf's website and have it fulfilled by a local participating retailer. The new site also will be accessible via the Company's main website, www.CallawayGolf.com

WOBURN, Mass.—(BUSINESS WIRE)—April 19, 2005—Skyworks Solutions, Inc.

(NASDAQ:SWKS), a global leader in analog, mixed signal and digital semiconductors for mobile communications applications, today announced Innovation to Go(TM), an e-commerce initiative which streamlines order processing, component selection and searches for its Linear Products portfolio. Enabled by a direct launch from the company's Web site at www.skyworksinc.com, the Innovation to Go (TM) system is available for placing online sample, evaluation boards, prototype and production orders with real-time visibility to selected product in stock

Table 9 Coding Examples

Classification Example

First-time The TJX Companies, Inc. (09/23/2004) The TJX Companies, Inc. (NYSE: TJX), the leading off-price retailer of apparel and home fashions in the U.S. and worldwide, today announced the launch of its e-commerce websites for T.J. Maxx and HomeGoods, www.tjmaxx.com and www.homegoods.com, marking the Company's first time selling over the Internet

Relaunch aQuantive, Inc. (02/15/2005) Avenue A/Razorfish, the largest independent interactive agency and an operating unit of aQuantive, Inc. (Nasdaq: AQNT), today announced the launch of its redesigned website, www.applevacations.com. For more than 35 years, Apple Vacations has offered convenient and affordable vacation packages to the most popular beach and ski destinations in the U.S

B2B Internet Gold (11/27/2006) Internet Gold, (Nasdaq NMS and TASE: IGLD) today announced that Smile.Media Ltd., its fully-owned subsidiary, and Yedioth Internet, operator of the popular Israeli YNET portal (www.ynet.co.il) have agreed to jointly establish a YNET-branded e-Commerce site

B2C Vail Resorts Inc (10/07/2002) Vail Resorts Inc. (NYSE: MTN) today announced new Internet booking services available at its www.snow.com site, providing visitors with enhanced capabilities for searching, selecting, and purchasing accommodation, activities, and other travel components

Intangible LivePerson, Inc. (04/19/2007) LivePerson, Inc. (Nasdaq: LPSN), a provider of real-time chat technology for customer support and sales, today announced the formal introduction of LivePersonalShoppers.com (www.livepersonalshoppers.com), a destination site designed for online consumers in need of live shopping assistance

Tangible Graco Inc. (07/10/2003) Graco Inc. (NYSE:GGG) has introduced an E-commerce site for new and existing customers to purchase lubrication products via the Internet 
Acknowledgements The authors would like to acknowledge the partial grants support from the research grant [grant numbers 72061127002] and the support from Center of Cyber Logistics in The Chinese University of Hong Kong.

\section{Declarations}

Conflict of interest No potential competing interest was reported by the authors.

\section{References}

1. Wang, Y., \& Herrando, C. (2019). Does privacy assurance on social commerce sites matter to millennials? International Journal of Information Management, 44, 164-177.

2. Liang, T.-P., \& Turban, E. (2011). Introduction to the special issue social commerce: A research framework for social commerce. International Journal of Electronic Commerce, 16, 5-14.

3. Kolbjørnsrud, V., Amico, R., \& Thomas, R. J. (2016). How artificial intelligence will redefine management. Harvard Business Review, 2, 1-6.

4. eMarketer, Worldwide Retail and Ecommerce Sales: eMarketer's Updated Forecast and New Mcommerce Estimates for 2017-2023, in, eMarketer, 2020.

5. Chaudhury, A., Mallick, D., \& Rao, H. R. (2001). Web channels in e-commerce. Communications of the ACM, 44, 99-104.

6. Xia, Y., \& Zhang, G. P. (2010). The impact of the online channel on retailers' performances: An empirical evaluation. Decision Sciences, 41, 517-546.

7. Saeed, K. A., Hwang, Y., \& Grover, V. (2002). Investigating the impact of web site value and advertising on firm performance in electronic commerce. International Journal of Electronic Commerce, 7, 119-141.

8. Konings, J., \& Roodhooft, F. (2002). The effect of E-business on corporate performance: Firm level evidence for Belgium. De Economist, 150, 569-581.

9. Steinfield, C., Adelaar, T., \& Liu, F. (2005). Click and mortar strategies viewed from the web: A content analysis of features illustrating integration between retailers' online and offline presence. Electronic Markets, 15, 199-212.

10. Subramani, M., \& Walden, E. (2001). The impact of e-commerce announcements on the market value of firms. Information Systems Research, 12, 135-154.

11. Dehning, B., Richardson, V. J., Urbaczewski, A., \& Wells, J. D. (2004). Reexamining the value relevance of e-commerce initiatives. Journal of Management Information Systems, 21, 55-82.

12. Dardan, M., Stylianou, A., \& Dardan, S. (2005). The valuation of eCommerce announcements during fluctuating financial markets. Journal of Electronic Commerce Research, 6, 312.

13. Barua, A., \& Mani, D. (2018). Reexamining the market value of information technology events. Information Systems Research, 29, 225-240.

14. Dewan, S., \& Ren, F. (2007). Risk and return of information technology initiatives: Evidence from electronic commerce announcements. Information Systems Research, 18, 370-394.

15. Tu, H.-J. (2012). Performance implications of internet channels in financial services: A comprehensive perspective. Electronic Markets, 22, 243-254.

16. Cheng, J.M.-S., Tsao, S.-M., Tsai, W.-H., \& Tu, H.H.-J. (2007). Will eChannel additions increase the financial performance of the firm?-The evidence from Taiwan. Industrial Marketing Management, 36, 50-57.

17. Konchitchki, Y., \& O’Leary, D. E. (2011). Event study methodologies in information systems research. International Journal of Accounting Information Systems, 12, 99-115.

18. Son, I., Lee, D., Lee, J.-N., \& Chang, Y. B. (2014). Market perception on cloud computing initiatives in organizations: An extended resource-based view. Information and Management, 51, 653-669.

19. Wijayana, S., \& Achjari, D. (2020). Market reaction to the announcement of an information technology investment: Evidence from Indonesia. Information and Management, 57, 103248. 
20. Geyskens, I., Gielens, K., \& Dekimpe, M. G. (2002). The market valuation of internet channel additions. Journal of marketing, 66, 102-119.

21. C. Wollscheid (2012) Rise and Bust of Dot.com Bubble, in: Causes, Characteristics, Examples, GRIN Verlag, Munich, pp. 27.

22. Dewar, R. D., \& Dutton, J. E. (1986). The adoption of radical and incremental innovations: An empirical analysis. Management Science, 32, 1422-1433.

23. McWilliams, A., \& Siegel, D. (1997). Event studies in management research: Theoretical and empirical issues. Academy of Management Journal, 40, 626-657.

24. Sorescu, A., Warren, N. L., \& Ertekin, L. (2017). Event study methodology in the marketing literature: An overview. Journal of the Academy of Marketing Science, 45, 186-207.

25. Ding, L., Lam, H. K., Cheng, T., \& Zhou, H. (2018). A review of short-term event studies in operations and supply chain management. International Journal of Production Economics, 200, 329-342.

26. Ferguson, C., Finn, F., \& Hall, J. (2005). Electronic commerce investments, the resource-based view of the firm, and firm market value. International Journal of Accounting Information Systems, 6, 5-29.

27. Agrawal, M., Kishore, R., \& Rao, H. R. (2006). Market reactions to e-business outsourcing announcements: An event study. Information \& Management, 43, 861-873.

28. Anthony, J. H., Choi, W., \& Grabski, S. (2006). Market reaction to e-commerce impairments evidenced by website outages. International Journal of Accounting Information Systems, 7, 60-78.

29. Dos Santos, B. L., Peffers, K., \& Mauer, D. C. (1993). The impact of information technology investment announcements on the market value of the firm. Information Systems Research, 4, $1-23$.

30. Lin, T.-C., Ku, Y.-C., \& Huang, Y.-S. (2014). Exploring top managers' innovative IT (IIT) championing behavior: Integrating the personal and technical contexts. Information \& Management, 51, 1-12.

31. Sun, K.-A., \& Kim, D.-Y. (2013). Does customer satisfaction increase firm performance? An application of American Customer Satisfaction Index (ACSI). International Journal of Hospitality Management, 35, 68-77.

32. Lohrke, F. T., Franklin, G. M., \& Frownfelter-Lohrke, C. (2006). The internet as an information conduit: A transaction cost analysis model of US SME internet use. International Small Business Journal, 24, 159-178.

33. Choshin, M., \& Ghaffari, A. (2017). An investigation of the impact of effective factors on the success of e-commerce in small-and medium-sized companies. Computers in Human Behavior, $66,67-74$.

34. Agatz, N. A., Fleischmann, M., \& Van Nunen, J. A. (2008). E-fulfillment and multi-channel distribution-A review. European Journal of Operational Research, 187, 339-356.

35. Kim, D. J., Ferrin, D. L., \& Rao, H. R. (2008). A trust-based consumer decision-making model in electronic commerce: The role of trust, perceived risk, and their antecedents. Decision Support Systems, 44, 544-564.

36. Johnson, M. E., \& Whang, S. (2002). E-business and supply chain management: An overview and framework. Production and Operations management, 11, 413-423.

37. Chang, H. H., Tsai, Y. C., \& Hsu, C. H. (2013). E-procurement and supply chain performance. Supply Chain Management: An International Journal, 18, 34-51.

38. Teece, D. J. (2010). Business models, business strategy and innovation. Long Range Planning, 43, 172-194.

39. Tushman, M. L., \& Anderson, P. (1986). Technological discontinuities and organizational environments. Administrative Science Quarterly, 31, 439-465.

40. Martínez-Ros, E., \& Orfila-Sintes, F. (2009). Innovation activity in the hotel industry. Technovation, 29, 632-641.

41. Fama, E. F., Fisher, L., Jensen, M. C., \& Roll, R. (1969). The adjustment of stock prices to new information. International Economic Review, 10, 1-21.

42. Lev, B., \& Zarowin, P. (1999). The boundaries of financial reporting and how to extend them. Journal of Accounting Research, 37, 353-385.

43. Chang, W., Franke, G. R., Butler, T. D., Musgrove, C. F., \& Ellinger, A. E. (2014). Differential mediating effects of radical and incremental innovation on market orientation-performance relationship: A meta-analysis. Journal of Marketing Theory and Practice, 22, 235-250. 
44. Tellis, G. J., Prabhu, J. C., \& Chandy, R. K. (2009). Radical innovation across nations: The preeminence of corporate culture. Journal of Marketing, 73, 3-23.

45. Ellis, N. (2010). Business to business marketing: Relationships, networks and strategies. Oxford University Press.

46. Kolis, K., \& Jirinova, K. (2013). Differences between B2B and B2C customer relationship management. Findings from the Czech Republic, European Scientific Journal, 4, 22-27.

47. Vakeel, K. A., Das, S., Udo, G. J., \& Bagchi, K. (2017). Do security and privacy policies in B2B and $\mathrm{B} 2 \mathrm{C}$ e-commerce differ? A comparative study using content analysis. Behaviour and Information Technology, 36, 390-403.

48. Mencarelli, R., \& Riviere, A. (2015). Perceived value in B2B and B2C: A comparative approach and cross-fertilization. Marketing Theory, 15, 201-220.

49. Coltman, T., Devinney, T. M., Latukefu, A. S., \& Midgley, D. F. (2002). Keeping e-business in perspective. Communications of the ACM, 45, 67-73.

50. Senn, J. A. (2000). Electronic commerce beyond the" dot com" boom. National Tax Journal, 53, 373-383.

51. Forrester (2019). US B2B eCommerce Will Hit $\$ 1.8$ Trillion By 2023, in, Forrester.

52. F. Ecom (2019). Project Future Ecom: State of the Art Report on "Global B2B E-Commerce in the US \& EU'.

53. MOC (2016). Chinese e-commerce market data monitoring report, in, 2016.

54. Lin, C., \& Lekhawipat, W. (2014). Factors affecting online repurchase intention. Industrial Management and Data Systems, 114, 597-611.

55. Mahadevan, B. (2000). Business models for Internet-based e-commerce: An anatomy. California Management Review, 42, 55-69.

56. Lian, J.-W., Liu, H.-M., \& Liu, I.-L. (2012). Applying innovation resistance theory to understand user acceptance of online shopping: The moderating effect of different product types. Computer Technology and Application, 3, 188-193.

57. Pham, T. S. H., \& Ahammad, M. F. (2017). Antecedents and consequences of online customer satisfaction: A holistic process perspective. Technological Forecasting and Social Change, 124, 332-342.

58. Aljifri, K. (2007). Measurement and motivations of earnings management: A critical perspective. Journal of Accounting, Business and Management, 14, 75-95.

59. Ross, S. A., Westerfield, R., \& Jordan, B. D. (2019). Fundamentals of corporate finance. New York: Tata McGraw-Hill Education.

60. Zhu, X., Xie, Y., Li, J., \& Wu, D. (2015). Change point detection for subprime crisis in American banking: From the perspective of risk dependence. International Review of Economics \& Finance, 38, 18-28.

61. Han, K., Oh, W., Im, K. S., Chang, R. M., Oh, H., \& Pinsonneault, A. (2012). Value cocreation and wealth spillover in open innovation alliances. MIS Quarterly, 36, 291-315.

62. Sambamurthy, V., \& Zmud, R. W. (1999). Arrangements for information technology governance: A theory of multiple contingencies. MIS Quarterly, 23, 261-290.

63. MacKinlay, A. C. (1997). Event studies in economics and finance. Journal of Economic Literature, 35, 13-39.

64. Im, K. S., Dow, K. E., \& Grover, V. (2001). A reexamination of IT investment and the market value of the firm-An event study methodology. Information Systems Research, 12, 103-117.

65. Henderson, G. V., Jr. (1990). Problems and solutions in conducting event studies. Journal of Risk and Insurance, 57, 282-306.

66. Brown, S. J., \& Warner, J. B. (1985). Using daily stock returns: The case of event studies. Journal of Financial Economics, 14, 3-31.

67. Patell, J. M. (1976). Corporate forecasts of earnings per share and stock price behavior: Empirical test. Journal of Accounting Research, 14, 246-276.

68. Barber, B. M., \& Lyon, J. D. (1996). Detecting abnormal operating performance: The empirical power and specification of test statistics. Journal of Financial Economics, 41, 359-399.

69. Black, B., \& Kim, W. (2012). The effect of board structure on firm value: A multiple identification strategies approach using Korean data. Journal of Financial Economics, 104, 203-226.

70. McWilliams, T. P., \& McWilliams, V. B. (2011). Another look at theoretical and empirical issues in event study methodology. The Journal of Applied Business Research, 16, 1-12. 
71. Aggarwal, N., Dai, Q., \& Walden, E. A. (2006). Do markets prefer open or proprietary standards for XML standardization? An event study. International Journal of Electronic Commerce, 11, $117-136$.

72. Benbunan-Fich, R., \& Fich, E. M. (2004). Effects of web traffic announcements on firm value. International Journal of Electronic Commerce, 8, 161-181.

73. Bilgihan, A., \& Wang, Y. (2016). Technology induced competitive advantage: A case of US lodging industry. Journal of Hospitality and Tourism Technology, 7, 37-59.

74. Oh, I., \& Park, G.-S. (2012). From B2C to B2B: Selling Korean pop music in the age of new social media. Korea Observer, 43, 365-397.

75. MOC (2020). The Ministry of Commerce holds a regular online press conference, in, 2020.

76. Braojos, J., Benitez, J., \& Llorens, J. (2019). How do social commerce-IT capabilities influence firm performance? Theory and empirical evidence, Information and Management, 56, 155-171.

77. Spithoven, A., Vanhaverbeke, W., \& Roijakkers, N. (2013). Open innovation practices in SMEs and large enterprises. Small Business Economics, 41, 537-562.

78. Saarani, A. N., \& Shahadan, F. (2013). The comparison of capital structure determinants between Small And Medium Enterprises (SMEs) and large firms in Malaysia. International Journal of Economics and Finance Studies, 5, 22-32.

79. Statista (2021). E-commerce share of total global retail sales from 2015 to 2024, in, 2021.

80. Duch-Brown, N., Grzybowski, L., Romahn, A., \& Verboven, F. (2017). The impact of online sales on consumers and firms. Evidence from consumer electronics. International Journal of Industrial Organization, 52, 30-62.

Publisher's Note Springer Nature remains neutral with regard to jurisdictional claims in published maps and institutional affiliations.

\section{Authors and Affiliations}

\section{Yang Lei ${ }^{1} \cdot$ Qiang Z hou $^{2} \cdot$ Waiman Cheung ${ }^{3} \cdot$ Xiling Cui $^{4}\left(\mathbb{D} \cdot\right.$ Ling Peng $^{5}$}

Yang Lei

leiy@sustech.edu.cn

Qiang Zhou

qzhou@hksyu.edu

Waiman Cheung

wcheung@cuhk.edu.hk

Ling Peng

pl@hbue.edu.cn

1 Department of Information Systems and Management Engineering, Southern University of Science and Technology, Shenzhen, Guangdong 518055, China

2 Department of Accounting, Hong Kong Shue Yan University, Hong Kong, China

3 Department of Decision Sciences and Managerial Economics, the Chinese University of Hong Kong, Hong Kong, China

4 Department of Business Administration, Hong Kong Shue Yan University, Hong Kong, China

5 College of Information Management and Statistics, Hubei University of Economics, Wuhan, Hubei, China 